\title{
Rice Production Monitoring System in the Philippines
}

\author{
Andy A. Lapada* \\ College of Computer Studies, Eastern Samar State University, Philippines; \\ lapada213@gmail.com
}

\begin{abstract}
Objectives: To develop an automated system that will monitor the rice production of the different Barangay in Borongan City and create a graphical statistics of rice production every season. Methods/Statistical Analysis: A software development methodology called Rapid Application Development (RAD) was utilized to develop an automated system. Software evaluation test were conducted using ISO 9126 software quality standard. Findings: The system were tested by experts and as a result, the software is in compliant with the ISO software quality standard with an average weighted mean of 4.60 with an adjectival rating as strongly acceptable. Application/Improvements: It is recommended that the developed system will be implemented in the Agriculture office in Borongan City, Philippines.
\end{abstract}

Keywords: Monitoring System, Philippines Rice Production, Rice Monitoring, Rice Production, Rice Production Monitoring System

\section{Introduction}

Food is the basic necessity of life. Rice is a vital food crop for the people of the world in general and Asians in particular. About $90 \%$ of the world's rice is produced and consumed in Asia pacific region.

In Asia, the rice cropping system is undertaking major adjustment to cope with increasing demography and the changing weather making rice monitoring aproblem ${ }^{1}$.

Furthermore, rice is considered as staple food for nearly 2.4 billion people in this region. Rice is socially, culturally, economically and environmentally important to many countries, especially in Asia. One of the factors in the production is rice production.

Philippines are one of many countries considered rice as staple food. Due to the unstable production of rice the food security is a concern of the people of this country especially the poorest of the poor ${ }^{2}$.

Philippine Rice Information System (PRISM) project aims to develop a monitoring and information system for rice production. PRISM's main purpose is to gather and organize information on rice area, yield, yield gaps and the causes of these yield gaps and to provide this information to key stakeholders for policy support.

In Borongan City, Agriculture Office takes active role in implementing research projects for institutional planning of rice production. Currently, the city agriculture use manual method to gather data. They gathered rice production data from farmers and this data are tabulated and monitored every season. Each data is compared every year to see the changes in its production. This kind of monitoring is tedious and very prone of data error. 
This is where the researcher takes advantage of creating a Monitoring System of the Rice production of the City of Borongan in Eastern Samar, Philippines. The study primarily aimed to produce a system that will automatically monitor rice production in the different barangay in Borongan.

\section{General Objective}

The study aimed to develop a system that will monitor the rice production of the City of Borongan specifically it aimed to:

\subsection{Develop and Integrate the Following Features}

- Monitor the rice production of the different Barangay in Borongan City.

- Create a graphical statistics of rice production every season.

- Generate a yearly rice production report.

- Search data of every rice producing barangay and compare the production in every barangay.
2.2 Using ISO 9126 Quality Model, Evaluate the Integrated System based on the following Parameters:

- Functionality;

- Reliability;

- Usability;

- Efficiency; and

- Maintainability

\subsection{Methodology}

\subsubsection{Software Development Methodology}

Rapid Application Diagram (RAD) Figure 1 is an objectoriented approach to systems cycle that includes a method of development as well as software tools $s^{3}$. It is high in Figure 2 terms of quality and in speed but low in cost; in short, it will enable quality software to be developed faster, saving valuable resources. RAD is subdivided into three major phases which are Requirements planning, Design Workshop and Implementation.

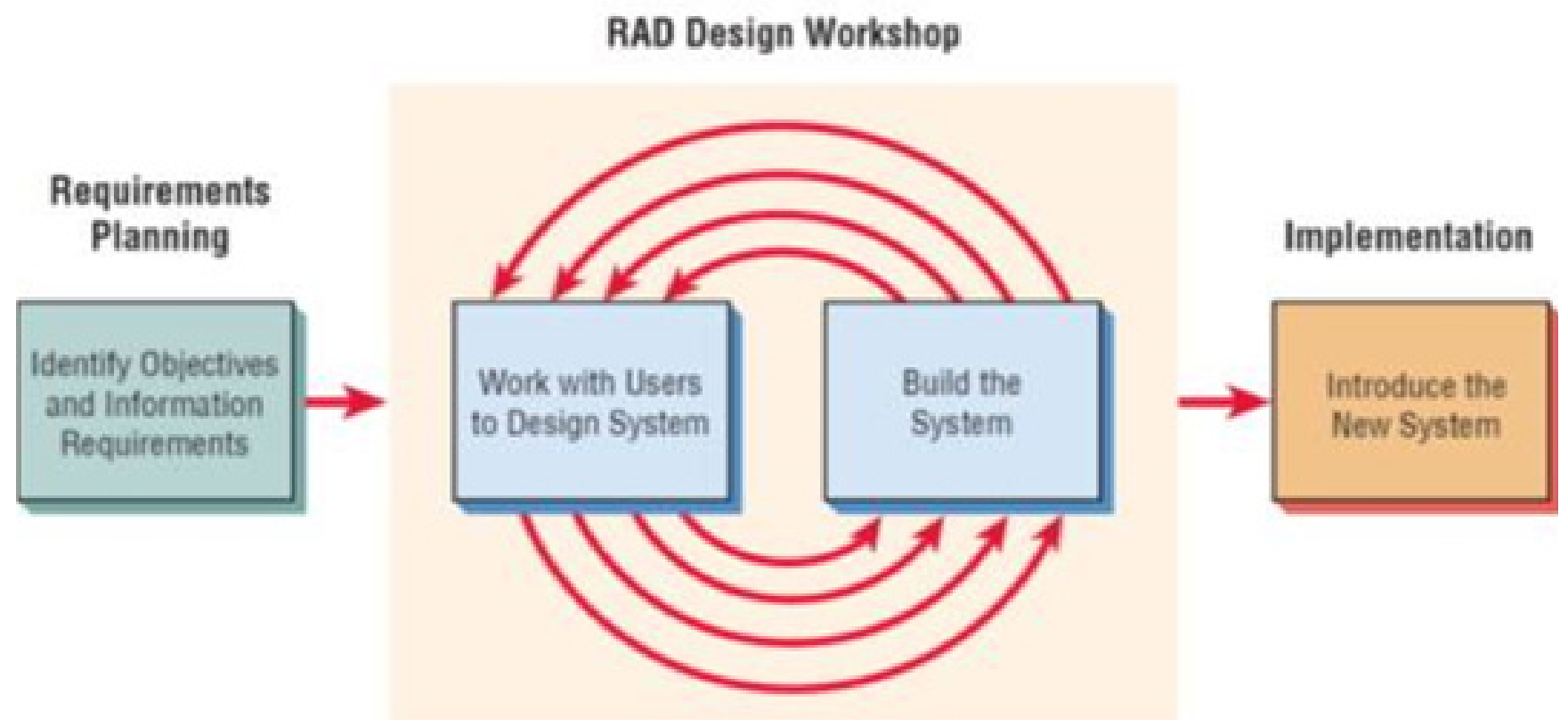

Figure 1. Rapid Application Development (Kendall and Kendall, 2005). 


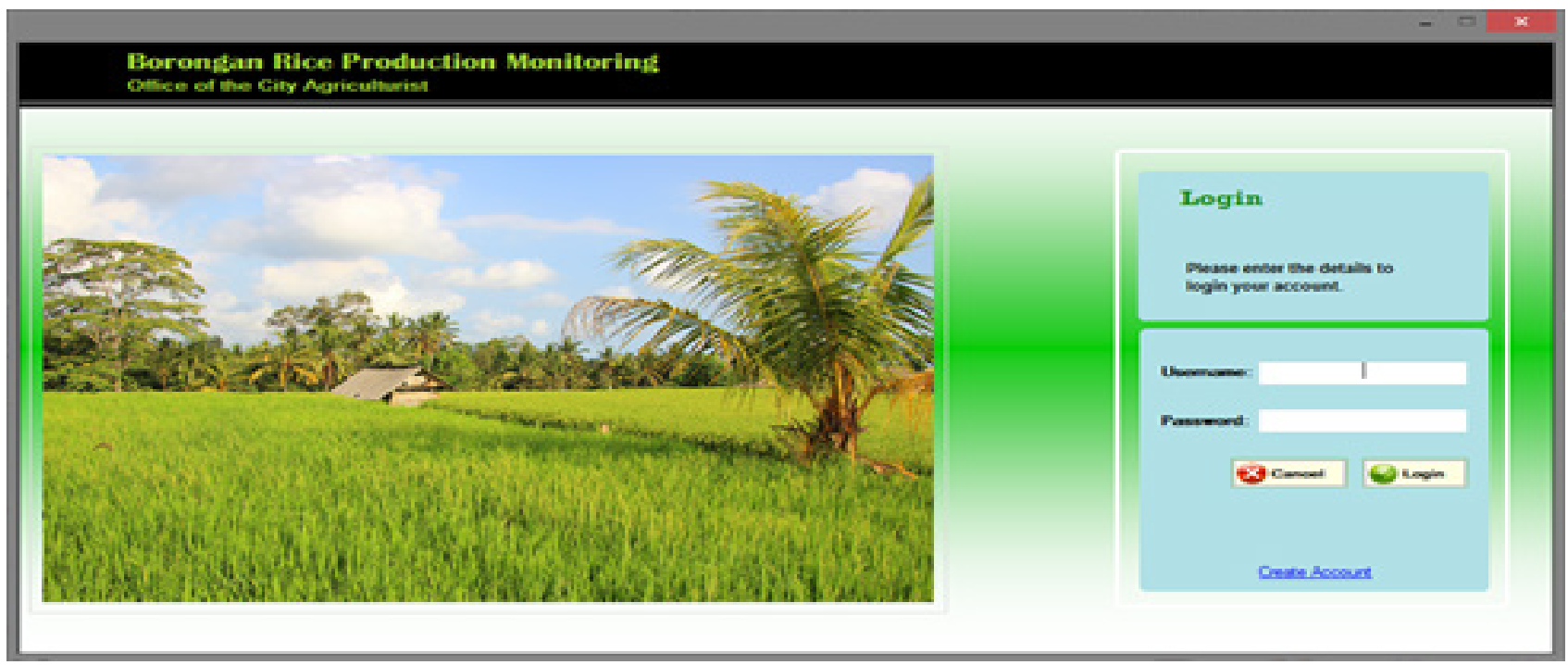

Figure 2. Login form.

\subsection{Data Analysis}

The descriptive statistics using the mean, frequency and percentage was employed to present the demographic characteristics of the respondents and level of the system effectiveness. The mean, frequency and percentage were used in the computation of the ISO 9216 evaluation to come up with the result. (Figure 3).

\subsection{Mean}

This is the average of the scores - the mathematical center of a distribution. It is use symmetrical, unimodal distribution of interval or ration scores. The formula for mean is:

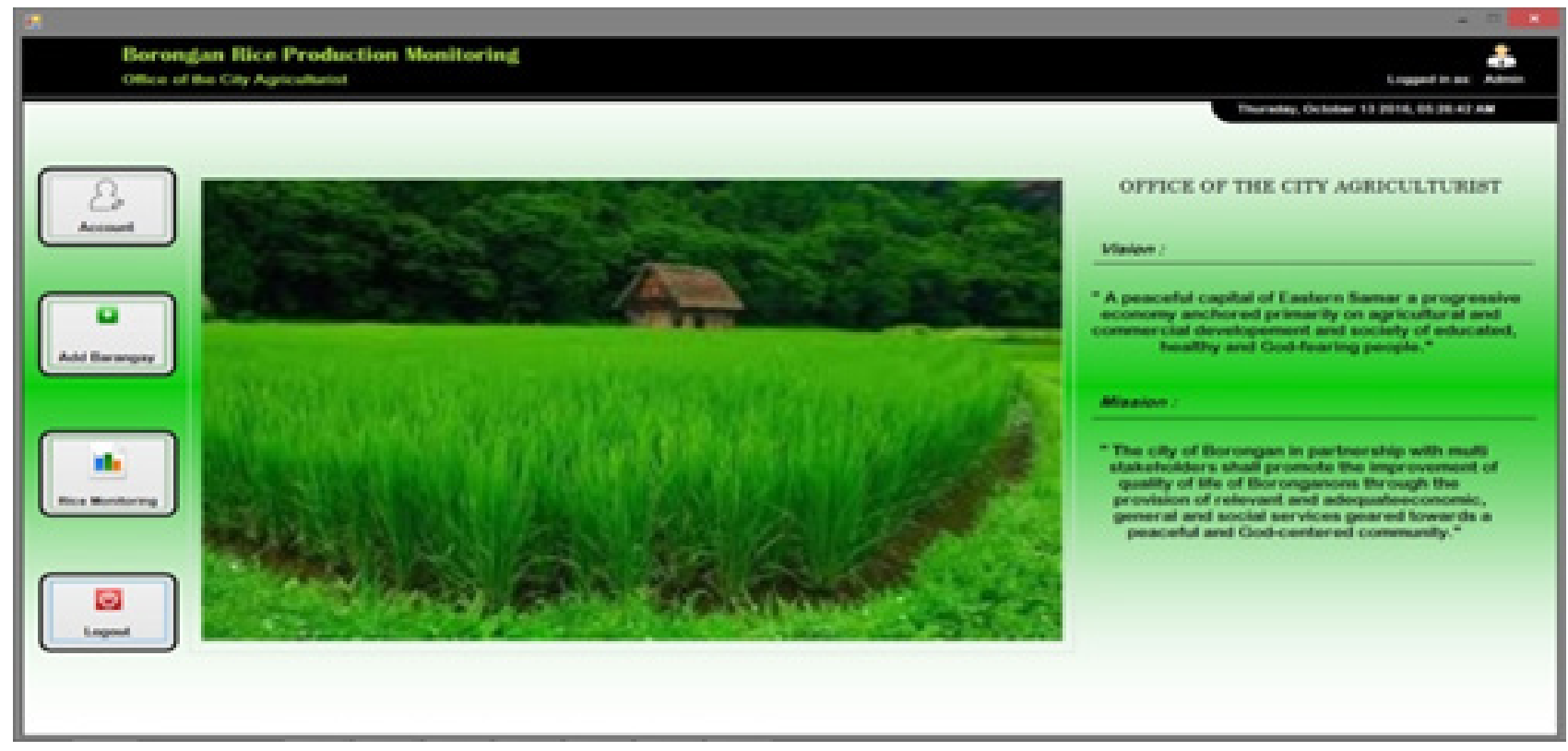

Figure 3. Rice monitoring system home page. 
Where:

$$
\chi=\frac{\sum \chi}{n}
$$

$\Sigma \chi=$ Sum of all scores

$\eta=$ Number of scores

\subsection{Percentage}

It defines as the part of expressed in hundredths. The formula for percentage is:

$$
\mathrm{P}=(\mathbf{n} / \mathbf{t}) X 100
$$

Where:

$$
\begin{aligned}
& \mathrm{P}=\text { percentage } \\
& \mathrm{n}=\text { number } \\
& \mathrm{t}=\text { total number of respondents }
\end{aligned}
$$

\subsection{Frequency Count}

Frequency Count allows user to specify the binning parameters "from Minimum to Maximum" and the step by increment or interval number. The tool will provide some reference value of the minimum, maximum and step.

\subsection{Coding Scheme}

The system was evaluated using the following scheme:

$4 \quad-\quad$ Agree.

3 - $\quad$ Slightly Agree.

$2 \quad-\quad$ Disagree.

$1 \quad-\quad$ Strongly Disagree.

The obtain mean was interpreted using the following: Numerical Rating Scale Adjectival Rating

$4.20-5.00 \quad$ Strongly Acceptable

$3.40-4.19 \quad$ Acceptable

$2.60-3.39 \quad$ Slightly Acceptable

$1.80-2.59 \quad$ Unacceptable

$-1.79$

\section{Results and Discussion}

Table 1 shows that all respondents answered yes $(n=20$, $100 \%)$ to all questions under the parameter functionality.

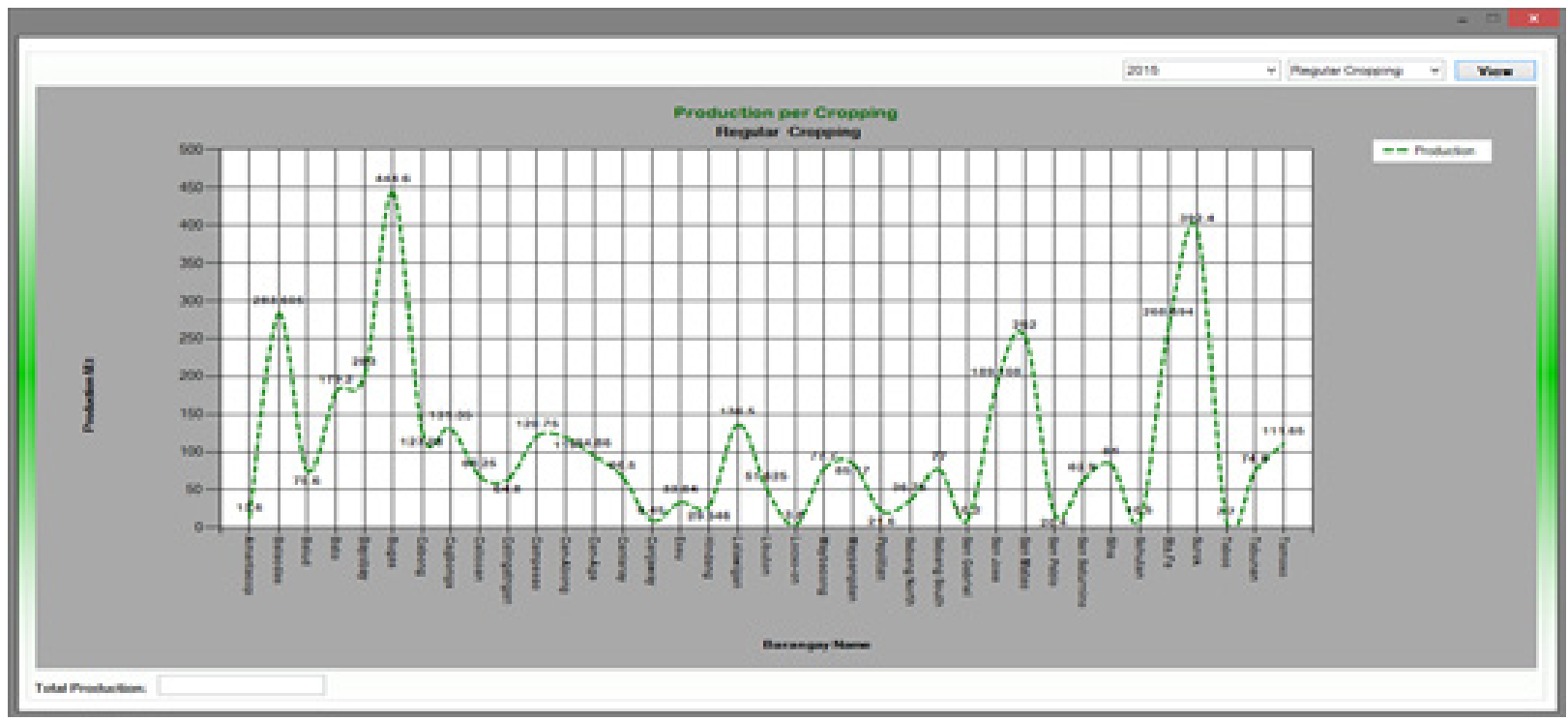

Figure 4. Production monitoring. 
Table 1. Interpretation for the parameter functionality

\begin{tabular}{|c|c|c|c|c|}
\hline \multicolumn{5}{|c|}{ Functionality } \\
\hline Question & $\begin{array}{l}\text { Frequency } \\
\quad(\text { Yes })\end{array}$ & $\begin{array}{l}\text { Percentage } \\
\text { (Yes) }\end{array}$ & $\begin{array}{l}\text { Frequency } \\
\text { (No) }\end{array}$ & $\begin{array}{l}\text { Percentage } \\
\text { (No) }\end{array}$ \\
\hline $\begin{array}{l}\text { The system can generate line chart for the } \\
\text { production. }\end{array}$ & 20 & $100 \%$ & 0 & - \\
\hline $\begin{array}{l}\text { The system can monitor production of } \\
\text { every rice producing barangay. }\end{array}$ & 20 & $100 \%$ & 0 & - \\
\hline $\begin{array}{l}\text { The system can compare the production of } \\
\text { rice in four barangay. }\end{array}$ & 20 & $100 \%$ & 0 & - \\
\hline The system can generate reports. & 20 & $100 \%$ & 0 & - \\
\hline $\begin{array}{c}\text { The system can search, update, delete, save, } \\
\text { edit and cancel data. }\end{array}$ & 20 & $100 \%$ & 0 & - \\
\hline
\end{tabular}

This means that all components needed by the end-user are present in the system. And this also means that the system has fully adhered to the standards of ISO in terms of functionality.

Table 2. Interpretation for the parameter reliability

\begin{tabular}{|c|c|c|c|}
\hline \multicolumn{4}{|c|}{ Reliability } \\
\hline Subparameter & Question & Mean & Interpretation \\
\hline Maturity & $\begin{array}{l}\text { The System avoids failure as a result of faults in the } \\
\text { software. }\end{array}$ & 4.8 & Strongly Acceptable \\
\hline Fault Tolerance & $\begin{array}{l}\text { The system maintains a specified level of performance } \\
\text { in cause of software faults or of infringement of its } \\
\text { specified interface. }\end{array}$ & 4.4 & Strongly Acceptable \\
\hline Recoverability & $\begin{array}{c}\text { The systems re-establish a specified level of } \\
\text { performance and recover the data directly affected in } \\
\text { the case of a failure. }\end{array}$ & 4.6 & Strongly Acceptable \\
\hline \multirow[t]{2}{*}{ Reliability } & $\begin{array}{l}\text { The system adheres to standards, conventions or } \\
\text { regulations relating to reliability. }\end{array}$ & 4.8 & Strongly Acceptable \\
\hline & Grand Mean & 4.65 & Strongly Acceptable \\
\hline
\end{tabular}

In Table 2, a grand mean of 4.65 interpreted as strongly acceptable was the result in the Reliability testing. All the sun parameters were rated as strongly acceptable. This 


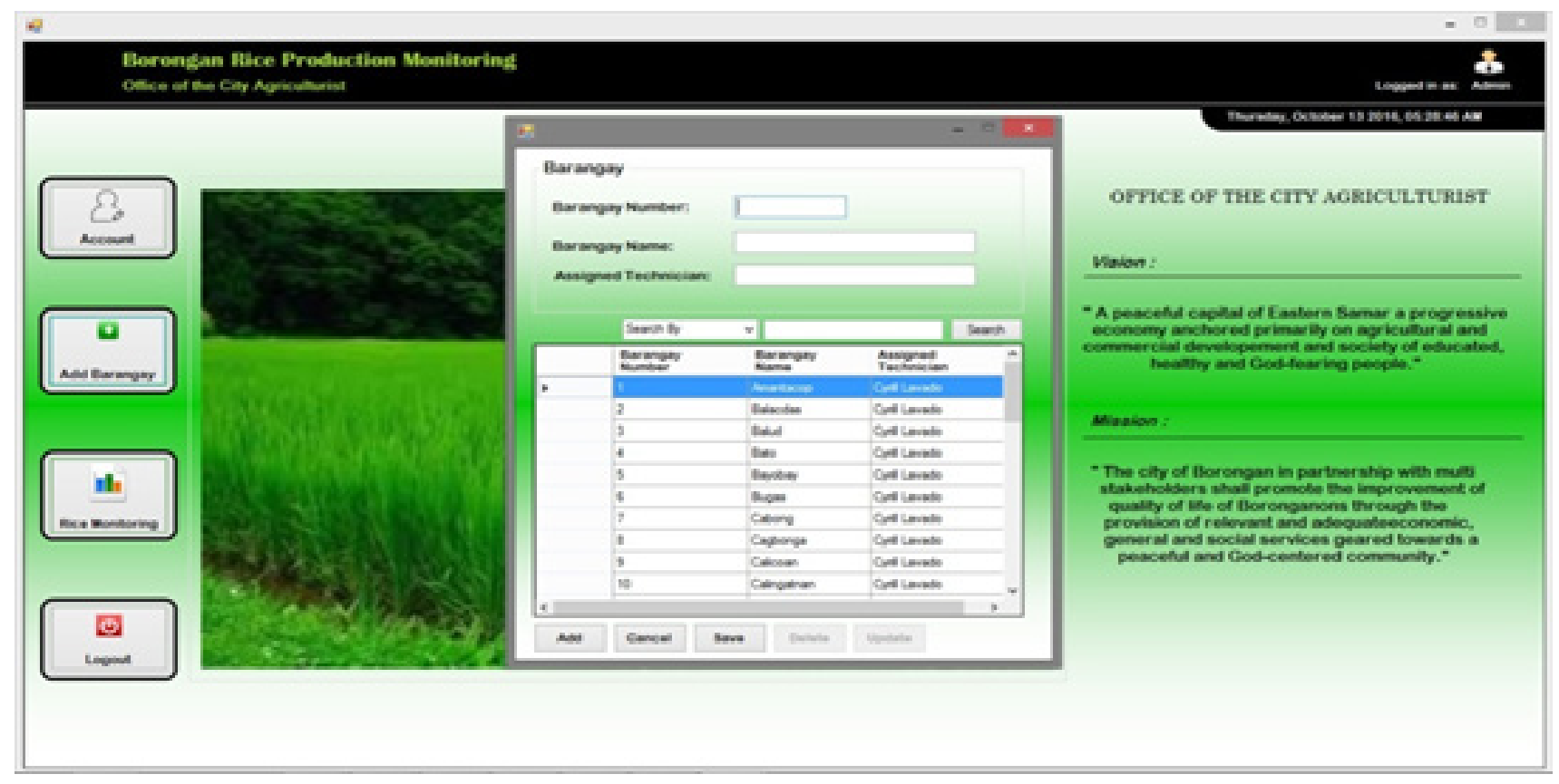

Figure 5. Barangay rice production comparison.

result implies that the system exhibits good measures in terms of recovering files and meet the ISO standard.
In Table 3 usability test, a grand mean of 4.64 interpreted as strongly acceptable was the result. All the sub

Table 3. Interpretation for the parameter usability

\begin{tabular}{|c|c|c|c|}
\hline \multicolumn{2}{|c|}{ Question } & Mean & Interpretation \\
\hline Subparameter & $\begin{array}{c}\text { The system enables the user to understand } \\
\text { whether the software is suitable, and how it can } \\
\text { be used for particular tasks condition of use. }\end{array}$ & 4.2 & Strongly Acceptable \\
\hline Usability & The system enables the user to learn its & 4.6 & Strongly Acceptable \\
\hline Learnability & The system enables the user to operate and \\
Opentrol it. & 4.8 & Strongly Acceptable \\
\hline Attractiveness & The system is attractive to the user. & 4.8 & Strongly Acceptable \\
\hline Usability compliance. & $\begin{array}{c}\text { The system adheres to standards, conventions, } \\
\text { style guides or regulations relating to usability. }\end{array}$ & 4.8 & Strongly Acceptable \\
\hline
\end{tabular}


Table 4. Interpretation for the parameter efficiency

\begin{tabular}{|c|c|c|c|}
\hline \multicolumn{2}{|c|}{ Question } & Mean & Interpretation \\
\hline Subparameter & $\begin{array}{c}\text { The system provides appropriate response } \\
\text { and processing times and throughout rates } \\
\text { when performing its function under stated } \\
\text { Time Benditions. }\end{array}$ & 4.8 & Strongly Acceptable \\
\hline Resource Utilization & $\begin{array}{c}\text { The system use appropriate amounts and } \\
\text { types of resources when the software } \\
\text { performs its function under stated } \\
\text { conditions. }\end{array}$ & 4.6 & Strongly Acceptable \\
\hline Efficiency Compliance & $\begin{array}{c}\text { The system adheres to standards or } \\
\text { conventions relating to efficiency. }\end{array}$ & 4.2 & Strongly Acceptable \\
\hline
\end{tabular}

parameters were rated as strongly acceptable. This result implies that the system is indeed usable. The system can easily be maneuvered and all its components are operational. Their basic designs are user- friendly. The system meets the ISO standard in terms of usability.
Efficiency test were resulted to a grand mean of 4.53 Table 4 interpreted as strongly acceptable. All three sub parameters were rated as strongly acceptable. This result implies that the system is efficient in terms of delivering results and handling data. This also means that the system

Table 5. Interpretation for the parameter maintainability

\begin{tabular}{|c|c|c|c|}
\hline \multicolumn{2}{|c|}{ Maintainability } & Mean & Interpretation \\
\hline Sub parameter & $\begin{array}{c}\text { Questions } \\
\text { Analyzability } \\
\text { software, or for the parts to be modified to be } \\
\text { identified. }\end{array}$ & 4.6 & Strongly Acceptable \\
\hline Changeability & $\begin{array}{c}\text { The system can enable a specified modification } \\
\text { to be implemented. }\end{array}$ & \multirow{2}{*}{4.4} & Strongly Acceptable \\
\hline Stability & $\begin{array}{c}\text { The system avoids unexpected effects from } \\
\text { modifications of the software. }\end{array}$ & Strongly Acceptable \\
\hline
\end{tabular}


Table 5 Continued

\begin{tabular}{|c|c|c|c|}
\hline Testability & $\begin{array}{c}\text { The system enables modified software to be } \\
\text { validated. }\end{array}$ & 4.6 & Strongly Acceptable \\
\hline $\begin{array}{c}\text { Maintainability } \\
\text { compliance }\end{array}$ & $\begin{array}{c}\text { The system adheres to standards or conventions } \\
\text { relating to maintainability. }\end{array}$ & 4.6 & Strongly Acceptable \\
\hline & Grand Mean & $\mathbf{4 . 6 0}$ & Strongly Acceptable \\
\hline
\end{tabular}

Table 6. Weighed mean and interpretation for all parameters

\begin{tabular}{|c|c|c|c|}
\hline $\begin{array}{c}\text { ISO 9126 Major } \\
\text { Parameters }\end{array}$ & Weighed Mean & Interpretation & Rank \\
\hline Reliability & 4.65 & Strongly Acceptable & 1 \\
\hline Usability & 4.64 & Strongly Acceptable & 2 \\
\hline Efficiency & 4.53 & Strongly Acceptable & 4 \\
\hline Maintainability & 4.60 & Strongly Acceptable & 3 \\
\hline Grand Mean & 4.60 & Strongly Acceptable & \\
\hline
\end{tabular}

fully adhered to the ISO standards in term of efficiency Figure 4.

Usability test resulted to a grand mean of 4.60 Table 5 interpreted as strongly acceptable. All sub parameters were rated as strongly acceptable. The system adhered to the standards of ISO in terms of maintainability.

The overall mean in all parameters in Table 6 got a grand mean of 4.60 interpreted as strongly acceptable. All of the major parameters (Reliability, Usability, Efficiency and Maintainability) were rated by the evaluators as strongly acceptable. Over-all the system adhered to the quality standards of ISO 9126 Figure 5.

\section{Conclusion}

Based on the computed results in all the series of software development and testing the following conclusions were drawn:

- The proponents were able to meet the objectives and user requirements by successfully developing and integrating the following components and modules:

- Monitor the rice production of the different Barangay in Borongan City.

- System that will create a graphical statistic of rice production every season. 
- System that can generate a yearly rice production reports.

- Search data of every rice producing barangay and can compare the production: by barangay, by cropping and by year.

- The software expert testing resulted to a grand mean of 4.60 that is interpreted as Strongly Acceptable. This means that the system adhered to the software quality standards of ISO 9126 and implies that the evaluators/userswas satisfied with the Borongan Rice Production Monitoring System.

\section{References}

1. Bouvet A, Le Toan T, Lam-Dao N. Monitoring of the rice cropping system in the Mekong Delta using ENVISAT/ ASAR dual polarization data. IEEE Transactions on Geoscience and Remote Sensing. 2009; 47(2):517-26. https://doi.org/10.1109/TGRS.2008.2007963.

2. Dawe D, Moya P, Casiwan C. Why does the Philippines import rice? Meeting the challenge of trade liberalization. International Rice Research Institute; 2006. p. 1-172.

3. Kendall KE, Kendall JE. Systems analysis and design. Camden, New Jersey; 2002. p. 1-601. PMid: 11846855. 